\title{
FRANCISCO MORENO GALVÁN, AUTOR DE LETRAS FLAMENCAS
}

\section{Francisco Moreno Galán, Author of Flamenco Lyrics}

\author{
Juan Diego MarTín CABEZA \\ Centro de Iniciativas Culturales de la Universidad de Sevilla \\ jdmcabeza@gmail.com
}

Recibido: 07/07/2019; Aceptado: 05/01/2020; Publicado: 31/12/2021

Ref. Bibl. JUAN DIEGO MARTÍN CABEZA. FRANCISCO MORENO GALVÁN, AUTOR DE LETRAS FLAMENCAS. 1616: Anuario de Literatura Comparada, 11 (2021), 77-97

RESUMEN: El pintor Francisco Moreno Galván (Puebla de Cazalla 19251999) compaginó en su trayectoria artística su faceta en torno a la pintura y la ilustración con la creación de letras flamencas para las voces de cantaores como José Menese, Miguel Vargas o Diego Clavel. Se analizan en este trabajo las claves principales de esa faceta creativa y su relación con la copla o letra flamenca popular, y también con otras creaciones de poetas reconocidos. En este sentido es importante resaltar la influencia de Antonio Machado Álvarez (Demófilo) y sus hijos Antonio y Manuel. Tanto el padre como los hijos fueron admirados y estudiados por Moreno Galván y nos ofrecen claves importantes a tener en cuenta en la obra letrística de nuestro autor. Se trata entonces de poner de manifiesto, por un lado, el necesario sabor popular que ha de tener la letra para el cante, pero también el peso de la tradición lírica castellana y su vínculo con esta forma poética.

Palabras clave: flamenco; tradición; jondo; letras; popular.

ABSTRACT: Francisco Moreno Galván (Puebla de Cazalla, Spain, 19251999) was a painter in which artistic career painting and drawing are combined 
with flamenco poetry, having written lyrics to cantaores (singers) such as José Menese, Miguel Vargas or Diego Clavel. The main cornerstones of this facet have been studied in this work, as well as the relationship with flamenco tradicional lyrics (copla) of Moreno Galván and other regarded poets. It is important to emphasise the influence of Antonio Machado Álvarez (Demófilo) and his sons Antonio and Manuel. The father as well as the sons were admired and studied by Moreno Galván and they offer significant keys to understand the artist's lyric work. The objective of such a paper, therefore, is to underline the inherent tradicional flavour in flamenco lyrics; but, on the other hand, the importance of Castillian lyrical tradition and its bounds with this poetic form.

Key words: flamenco; tradition; jondo; lyrics; popular.

Pero es indudable que por último se afirmará en definitiva el artista que arrogante y sencillamente afronte el peligro de ser entendido de todos, el que como los más grandes poetas de todos los siglos tenga algo que decir lo mismo a la muchedumbre que al hombre selecto; y podemos esperar que, aún más allá, una educación más elevada, afectiva e integral del hombre podrá traer que la poesía vuelva a ser sentida en común, expresando y uniendo emociones colectivas, como en los mejores días de otras épocas de gran florecimiento que hoy miramos con admirativa envidia; y siendo entonces el arte lo más y el artista lo menos, podrá renacer cualquier forma de poesía anónima y tradicional, pues la vida de ésta no depende de la cronología de la cultura, sino de la orientación ideal del hombre. (Menéndez Pidal 1973, 356)

\section{BREVE APUNTE BIOGRÁFICO}

Entre otras muchas, dos son las facetas más importantes que desarrolló Francisco Moreno Galván en su vida. Por un lado, la pintura, a la que se dedicó desde niño y que podríamos decir que fue su sustento durante toda su vida. Por otra parte, su desmedida afición al flamenco y a todo lo que lo rodeaba más allá del toque, baile y cante en el que primordialmente, se manifiesta. Ese concepto, afición, que en su significado ha ido perdiendo con el paso de los siglos la fuerza etimológica de la affectio latina para desembocar en el inane hobby anglosajón, mantiene en el flamenco un honroso prestigio. El aficionado al flamenco no es el que dedica parte de su tiempo de ocio a un divertimento musical, es el que se entrega y trata de comprender el máximo de sus vericuetos expresivos, el que estudia y se desvive por desentrañar las múltiples variantes geográficas, estilísticas, interpretativas... El aficionado, el aficionao en el argot, es alguien digno de 
admiración, pero también alguien que puede ver cómo su vida se desvía en el camino que parecía estar previsto, que es lo que precisamente pasó con Moreno Galván.

Nacido en la Puebla de Cazalla el 1 de enero 1925, desde muy joven parecía clara su predisposición al dibujo. Esas aptitudes no pasaron desapercibidas entre la corporación municipal y a la temprana edad de doce años, y teniendo en cuenta las pocas posibilidades económicas de su padre, a la sazón maestro de la Villa, el Ayuntamiento dispuso conceder una beca al joven Francisco para sufragar estudios de pintura en Sevilla. Esa beca hizo que toda la familia se mudase a la capital para acompañar al niño impulsando así también la carrera de otro hijo, José María, dos años mayor que Francisco, y cuya influencia fue fundamental en la formación pictórica de su hermano. José María llegaría a ser con el tiempo un reconocido crítico de arte en revistas como Artes, Goya o, años más tarde, Triunfo. Francisco siempre compaginó su carrera de pintor con su afición al flamenco. Esto se intensificó cuando a raíz de un premio conseguido a través de la Diputación de Sevilla se muda a Madrid. Entra allí en contacto, por un lado, con flamencos andaluces que desarrollaban allí sus carreras (Pepe de la Matrona, Perico del Lunar, Pericón de Cádiz, Rafael Romero...); por otra parte, es punto de encuentro con artistas (andaluces o no) que dedicándose a facetas artísticas diferentes mantenían un contacto importante con el mundo del flamenco (Jorge Oteiza, José Manuel Caballero Bonald, Fernando Quiñones...). Esa conexión, más la paulatina toma de conciencia política en el Madrid de principios de los años sesenta, será el caldo de cultivo en el que Francisco Moreno experimente su ideario Jondo. Para ello fue fundamental uno de los viajes que realizó a su pueblo, donde conoció a un joven cantaor, José Menese, al que se propuso introducir en los ambientes flamencos de Madrid. El encuentro con Menese supuso que Moreno Galván dedicara cada vez más tiempo al flamenco encargándose de alentar al joven cantaor y produciendo su incipiente discografía, comenzando con la escritura de nuevas letras que hablaban del contexto social, político y personal en el que ambos habían crecido.

Francisco Moreno Galván compaginó a partir de mediados de los años sesenta esa faceta de producción discográfica con la pintura, la poesía, y el desarrollo de otras manifestaciones como el urbanismo o el interés por la cultura popular, que pudo desarrollar años más tarde cuando, una vez llegada la democracia, regresó a su pueblo y fue elegido concejal por el Partido Comunista de Andalucía en las primeras elecciones locales democráticas. En su pueblo puso también las bases para una reunión de cante jondo, para lo cual siguió el modelo impuesto por Falla y Lorca en 1922 en el Concurso de Cante Jondo, que aglutinó a los más importantes artistas 
flamencos de la época, pero también a otros muchos pintores, músicos, poetas e intelectuales alrededor del flamenco con una intención protectora de algo que consideraban en peligro de extinción.

Francisco Moreno Galván experimentó, pues, en diferentes ámbitos artísticos siempre teniendo como centro de su interés el flamenco. La forma en la que entendía la expresión artística era eminentemente pragmática, era consciente de la capacidad de transformar, de expresar, de mover y conmover al espectador, a quien tenía una experiencia con el flamenco más jondo; y esa capacidad la desarrolló con las herramientas del arte contemporáneo, pero desde un respeto absoluto por la tradición. En ese sentido es muy esclarecedora la forma en la que representa el flamenco en la cartelería que realiza para anunciar las reuniones de cante jondo. Como en el cartel de Manuel Ángeles Ortiz para el concurso de Granada de los años veinte, se trata de actualizar elementos simbólicos y comprensibles para cualquier espectador desde una ejecución contemporánea.

Cuando Francisco vuelve a su pueblo, abandona de alguna manera esa faceta de producción discográfica en la que influenció la carrera de otros artistas como Miguel Vargas o Diego Clavel, y se centró más en la faceta política desde las posibilidades que le ofrecía su cargo de concejal de Cultura, o, más tarde, como dinamizador de la cultura local y, también, rescatador de los viejos oficios de construcción que pone en práctica en la arquitectura local, la nomenclatura de las calles o una faceta tipográfica en publicaciones locales, pero que él cuidaba hasta sus últimos detalles. Aquejado de una enfermedad que lo postró cerca de una década, apenas sin poder moverse o comunicarse, murió el 21 de junio de 1999 en su pueblo.

\section{Elementos Característicos en las letras de Moreno GalváN}

Cuando en 1963, poco antes de ganar en Córdoba el premio por seguiriyas Tomás el Nitri, se presenta la posibilidad de grabar un disco con la casa RCA Víctor, surge entre Moreno Galván y Menese una cuestión fundamental: «¿Y ahora qué cantamos?».

Se trataba de una apuesta arriesgada teniendo en cuenta el corte de cantaor que pretendía llegar a ser José Menese, muy fiel a la tradición en la expresividad y en los estilos que interpretaba. El aficionado por lo general hace una valoración del cante en función a la capacidad expresiva del cantaor con respecto al ideal que tiene interiorizado en torno al estilo interpretado. Si a eso se le añade la capacidad expresiva del contenido de la letra, su texto, requiere una especial intensidad expresiva unida a la capacidad de «decir» el cante. En este caso, tanto al cantaor como al autor de 
la letra les interesaba que hubiese un vínculo especial entre lo que se canta y cómo se canta. Moreno Galván lo dejó escrito en un prólogo a sus letras que no llegó a publicar en vida:

Ya sé que con los problemas ajenos nos identificamos en el cante, y los hacemos nuestros; ya sé que la comunicación se establece no por lo que diga la letra, sino -y esto en el cante es esencial- por la forma de expresarlo, por la queja y cómo se queja, pero yo me he preguntado siempre y siempre me respondía la misma cosa: Una persona tendrá más posibilidades de transmitir una queja si a quien duele es a él. (Martín Cabeza 2018, 287)

La primera motivación para escribir nuevas letras es, pues, la necesidad de buscar mayor poder expresivo en ellas por la vivencia personal del intérprete. Al fin y al cabo, esta motivación es fiel a muchas letras del cante creadas, o bien desde la experiencia vital del propio intérprete, o bien por alguien que observa y traduce a lenguaje poético lo que ocurre en un determinado contexto. En este sentido, el escultor Eduardo Carretero se refiere a los inicios de Moreno Galván en los rudimentos métricos:

Los gitanos han cantado siempre refiriéndose a su vida y Francisco se decidió a hacer también letras de su propia vida para Pepe, pero no sabía cómo era eso. Él y yo íbamos juntos entonces a todas partes, por temas de arte, de exposiciones. Una vez íbamos a Pamplona y, en el camino, le enseñé lo que eran los versos y las estrofas... Entonces, los coches no eran rápidos, los viajes eran largos. Había tiempo para todo. Cuando bajamos del dos caballos, ya tenía Francisco hecha su primera copla:

Mi pare y mi hermano Diego

zapateros como yo,

y en casa de zapatero,

descarcito andamos tós. (García Gómez 1996: 51)

Esa es, de hecho, la primera letra de la que se tiene noticia escrita por Moreno Galván. Una letra estrechamente vinculada a la biografía de José Menese y, por tanto, como escribía Francisco más arriba, susceptible de ser cantada con más expresividad. Pero al mismo tiempo hay una serie de detalles sobre estas letras sobre los que debemos detenernos. En primer lugar, cabe destacar la preminencia de lo fonético sobre lo sintáctico. Eran letras para ser cantadas. En ningún caso tenían ninguna vocación poética puesto que no estaban hechas para ser publicadas ni leídas. De hecho, las transcripciones que se conservan de algunas de estas letras son una guía para que el intérprete, en este caso Menese, pueda comprender cómo debe ser la pronunciación de los sintagmas con el fin de cuadrar métricamente el cante en cuestión: 
Mi casa es un desarreglo, coloraíto mi pare, mi mare, de pelo negro.

Pero lo verdaderamente interesante de la obra letrística o poética de Moreno Galván es cómo paulatinamente va asumiendo elementos de la tradición poética española ${ }^{1}$, con la misma naturalidad con la que, entendemos, el propio corpus textual del flamenco es parte de esa tradición por derecho propio.

Me ha gustado mucho leer. Conozco gran parte de la poesía popular española, porque qué duda cabe que conocer a los grandes sirve de ayuda y aporta riqueza. Me encanta la ternura de San Juan de la Cruz y admiro la valentía y la dureza de Quevedo, tanto que llegué a pintarle y me sirvió de espejo en el disco Andalucía 40 años. También a Lope de Vega; en él me he inspirado en varias ocasiones en algunas grabaciones. Y cómo no mencionar a Martín Fierro; el disco Ama todo cuanto vive es un intento, a mi manera, inspirándome en esta obra. Tampoco puedo dejar atrás a Machado, Lorca, Alberti...2.

En este fragmento, Moreno Galván desvela las influencias fundamentales en su poesía. En sus palabras, no se sabe bien dónde empieza la admiración de apasionado lector y dónde termina el aprendizaje de poeta. La biblioteca de cualquier persona es, en cualquier caso, una buena forma de conocerla a fondo; más aún, es una de las mejores formas de conocer a un artista. Siendo esto así, haber tenido la oportunidad de acceder y consultar la biblioteca de Francisco Moreno Galván nos ha dado claves importantísimas no solo de sí mismo como lector, sino también sobre su poesía.

La primera influencia reside en lo que él llama poesía popular. En este sentido, se refiere al romancero y también a las colecciones de coplas de finales del siglo XIX. Moreno Galván recurría en numerosas ocasiones a la Flor Nueva de Romances Viejos de Menéndez Pidal, buscando sustento métrico y rítmico a buena parte de sus letras. Teniendo en cuenta que el título mismo de la obra le resultaba acertado, cabe hacer una comparación entre este y el título de uno de los primeros discos de José Menese: Renuevo de cantes viejos. El espíritu, la intención, en ambos casos, son los mismos. Decía Menéndez Pidal en el prólogo a su obra:

1. Puede ahondarse en el desarrollo de estas influencias en el capítulo "Orígenes, influencias y variedad poética", MARTín CABEZa 2018.

2. Moreno Galván, Francisco. Sevilla Flamenca, 1992, n. ${ }^{\circ} 84$, p. 82. Entrevista realizada por Francisco González Ramírez. [González Ramírez, Francisco. «Entrevista a Francisco Moreno Galván». Sevilla Flamenca, 1992, n. ${ }^{\circ}$ 84, p. 82.]???¿¿̨no va en la bibliografía? Pasar a bibliografía. 
El que compare los textos incluidos en esta Flor Nueva de Romances [...] sentirá extrañeza ante otras variantes que le son totalmente desconocidas; la mayoría de estas proceden de textos antiguos ignorados por los críticos antedichos, o de nuevas versiones modernas obtenidas de la tradición oral; algunas son de mi propia inventiva. Al introducir esas variantes creo que no hago sino seguir los mismos procedimientos tradicionales por los que se han elaborado los textos conocidos. [...] La tradición, como todo lo que vive, se transforma de continuo: vivir es variar. (Menéndez Pidal 1959, 47)

Estas palabras podrían estar suscritas perfectamente por Moreno Galván y dan cuenta exacta de su filosofía estética en lo concerniente a la tradición de la copla flamenca y su necesaria evolución. Su disco Renuevo de cantes viejos trata de ser precisamente una reivindicación de la renovación temática en un ejercicio al mismo tiempo de la recuperación de cantes poco frecuentados en aquel momento (año 1970).

Pero la influencia del romancero no se queda en la superficie, sino que llega a desempeñar un papel importantísimo en la creación de letras para el cante. La colombiana interpretada por José Menese en el disco Cantes de ida y vuelta (Pasarela, PDR-140. 33 rpm, 1985) es un excelente ejemplo de dicha influencia, cuando no mero rescate, del romancero para el cante. Así, la primera estrofa ya desde su inicio:

A dónde va esa mulata tan galana a dónde va, si hace diez años que falta nadie la conocerá; va a lucir cinta de plata en la fiesta de San Juan. (Moreno Galván 1998, 203)

Tiene su correlato en este romance:

¿A dónde va el caballero de punta en blanco y galán? -A las justas de Zamora por las fiestas de San Juan. De allí partí hace diez años, ya no me conocerán... (Piñero, Baltanás y Pérez Castellano 1998, 192)

Más reconocible es esta estrofa en la misma colombiana:

Dos olivitas nacieron de claro y verde olivar, crece el uno, crece el otro y ambos iban a la par, 
los ramos que se juntaban

besos y abrazos se dan. (Moreno Galván 1998, 203)

Con este otro romance que, a su vez, tiene un precedente en el conocido «Romance del Conde Olinos»:

De ella nació verde oliva, y del otro un olivar crece el uno, crece el otro, ambos iban a la par.

Cuando hacía aire de arriba ambos se iban a abrigar; cuando hacía aire de abajo ambos se iban a besar. (Menéndez Pidal 1944, 72)

Dentro de lo que Moreno Galván llama poesía popular, también están contenidas las colecciones de coplas y cantes de finales del siglo XIX, que poseía y conocía bien: Demófilo, Balmaseda, Rodríguez Marín...; de todas ellas, sin embargo, tenía especial predilección por la de Demófilo. En este caso, con frecuencia, optaba por la inclusión de una letra que le interesaba entre las creadas por él:

\section{Molinero que agua espera \\ y el trigo le pudre el viento, saque el molino del agua \\ y que muela con el viento ${ }^{3}$.}

Otras veces, recurre, en contraste, a un cante ya grabado que le haya conmovido. Menese canta, en este sendero, una cabal del Fillo con la siguiente letra de la Rubia de las Perlas:

Y salí por la puerta

salí renegando,

de cuantos santitos tiene

el cielo y la tierra .

Continuando con la nómina de poetas por los que Francisco Moreno Galván expresó su admiración, cabría hablar forzosamente de san Juan de la Cruz, Quevedo y Lope de Vega, fundamentales en la historia de la

3. Letra popular inserta en los tientos «Fe, coraje y esperanza» del disco Firme me mantengo, de José Menese.

4. En Demófilo «Aqueya mañana / que me lo ijeron / yo reniego de cuantos santitos tiene / la tierra y el sielo». En MaCHAdO Y y Álvarez 1975, p. 158. 
literatura española. En primer lugar, la posible influencia de san Juan de la Cruz no es fácilmente identificable. Quizá porque la poesía del místico español es tan personalísima que, si acaso, podemos entrever en Francisco Moreno determinados destellos que tienen que ver con la manera de plantear la letra desde un anhelo por el reencuentro y una tristeza desesperada ante la ausencia:

Mi casa vacía, sin ti y sin tu aliento, te están echando de menos -por los pasitos que en ellos dabaslos ladrillitos del suelo.

Es esta una letra extraña dentro de la obra de Moreno Galván, quizá por ese halo de nostalgia que desprende. La diferencia aquí entre letra y poesía se hace prácticamente invisible.

Quevedo, sin embargo, está más presente en Moreno Galván. No solo lo pintó, sino que lo admiró en su valentía personal y en su desenfado a la hora de enfrentarse a la poesía con una actitud burlesca que se tornaba certera crítica o una crítica feroz que se hacía burla. Como estandarte personal pudiera haber llevado Moreno Galván el principio del conocido poema de Quevedo dedicado al conde duque de Olivares:

No he de callar, por más que con el dedo, ya tocando la boca, o ya la frente, silencio avises, o amenaces miedo. ¿No ha de haber un espíritu valiente? ¿Siempre se ha de sentir lo que se dice? ¿Nunca se ha de decir lo que se siente?

El Quevedo que interesa a Moreno Galván es el testigo perfecto de su tiempo. El que ve cómo se desmorona todo y es capaz, en perfecta y sutil manera, de escribirlo y describirlo:

Yace aquella virtud desaliñada, que fue, si rica menos, más temida, en vanidad y en sueño sepultada. Y aquella libertad esclarecida, que en donde supo hallar honrada muerte, nunca quiso tener más larga vida. Y pródiga del alma, nación fuerte, contaba por afrentas de los años envejecer en brazos de la suerte. ("Epístola satírica y censoria contra las costumbres presentes de los castellanos", Quevedo 1980, 79) 
Esta poesía dura y testimonial le sirve en el disco publicado en 1978, Andalucía 40 años, que es un recuento de las atrocidades sociales e históricas del franquismo y de su repercusión en nuestra región. El disco en su integridad y sus letras son un reflejo de esa condición dura, recordatoria, testimonial, de la poesía quevedesca:

Se hizo el reparto de paz tan alabado y bendito, sin derecha y sin izquierda: dando más bienes al rico y a los pobres más miserias.

Entre jambre y jambre del pueblo $\mathrm{y}$ altos jumos victoriosos empezaron los cuarenta. Entre jambre y calabozo ajuste y pago de cuentas. Comenzó un largo rosario de miedos y de miserias, de pan negro y letanías, de orden y de derechas y una infame beatería.

Reseñamos otra vertiente poética de Quevedo que interesó a Moreno Galván y de la que se nutrió para sus letras. Se trata de la poesía burlesca, tan en boga en el Siglo de Oro:

Ministril de las ronchas y picadas, mosquito postillón, mosca barbero, hecho me tienes el testuz harnero, y deshecha la cara a manotadas.

Trompetilla, que toca a bofetadas, que vienes con rejón contra mi cuero, Cupido pulga, chinche trompetero, que vuelas comezones amoladas. ("Al mosquito de la trompetilla", Quevedo 1992)

El letrista lo emplea en el retrato al dictador Franco por alegrías:

Triquitraque, paticorto, pájaro tripón sin plumas y con espolones de peleón.

Te vi saltando en el coto de la nación.

Que por las calles que pasas 
te van poniendo

trapitos de colores

y sahumerio.

O también esta perla dedicada a cierto crítico flamenco por guajiras:

Tarambana, sacatrapos,

charlatán, parlicansino.

Raja, rompe y pierde el tino

y no sabe lo que destruye,

con lo que opina y arguye

no nos deja oveja sana;

corta orejas, patas, lanas

$\mathrm{y}$ al final de este destrozo,

cobra más por cada trozo

que el amo por la manada.

En un tercer nivel de fuentes, la presencia de la poesía de Lope de Vega es más que evidente en Moreno Galván. Seguramente porque la estructura y temática de Lope alcanza el aroma de lo popular que buscaba incansablemente el pintor y poeta de La Puebla de Cazalla. En las cantiñas tituladas "Anda cerca la tormenta", del disco Los que pisan la tierra (1974), introduce una estrofa de las «Seguidillas del Guadalquivir", de Lope:

Vienen desde Sanlúcar, rompiendo el agua,

a la torre del oro

barcos de plata. (Moreno Galván 1998, 117)

Sobre el mismo poema realiza una pequeña variación en unas sevillanas que años más tarde grabaría Raúl Montesinos en su disco Arquillo Viejo (Fonocruz, 2009)5:

Río de las velas blancas, orillas de ramos verdes, hermano de torres de oro señor de los cuatro puentes.

Quién te pasara aunque las zapatillas se me mojaran.

5. Cabe precisar aquí que las sevillanas son un tipo de cante cuya estructura métrica en sus letras proviene directamente de la seguidilla castellana. 
La primera parte es creación de Moreno Galván inspirada en las seguidillas de Lope; la estrofa en cursiva es una pequeñísima variación de:

¡Quién te pasase

sin que la mi servilla

se me mojase! («eguidillas del Guadalquivir», Lope de Vega 1951)

El cambio no resta valor expresivo a la copla y, sin embargo, la actualiza y la hace más cantable.

Hemos podido ver hasta ahora los vínculos de las letras flamencas de Moreno Galván con la tradición poética española desde los romances hasta el Siglo de Oro. Pasaremos a continuación a ver diferentes correspondencias con autores más cercanos a su tiempo de los que también se nutrió para la forja y génesis de su corpus poético.

\section{INFLUENCIAS DE LA POESÍA MODERNA}

En nuestro periplo por las influencias de fuentes en la poesía de Moreno Galván estamos siguiendo prácticamente lo que él declaró en su entrevista para la revista Sevilla Flamenca en el año 1993. De hecho, esas influencias son bastante claras en determinados momentos de su obra. Es fácilmente reconocible, en este contexto, la admiración que siente por la obra de José Hernández (1834-1886) El gaucho Martín Fierro no solo en el estilo, sino también en el tono melancólico y siempre digno del poeta que canta desde la soledad, la libertad y el pueblo. Francisco Moreno tituló, efectivamente, uno de los discos de José Menese Ama todo cuanto vive, en claro homenaje a uno de los poemas del libro de Hernández:

Ama en el fondo del mar

el pez de lindo color;

ama el hombre con ardor,

ama todo cuanto vive.

De Dios vida se recibe

y donde hay vida, hay amor.

Esa dignidad humana, pero también esa comunicación íntima con la naturaleza, se encuentra en Moreno Galván:

Ay, brote la espiga,

la yerba y la espiga brote,

brille el sol, brillen los mares,

espejos al horizonte. 
Daremos vida a la vida a la alondra y a las flores y a la paloma su oliva.

El libro de José Hernández se convirtió en Argentina en un icono íntimo, siendo imitado, entre otros, por Borges en su cuento "El fin". Junto al autor de El Aleph, Leopoldo Marechal escribió un ensayo titulado "Simbolismos de Martín Fierro» en el que ofrecía una lectura del texto en clave alegórica. El Martín Fierro es una obra en la que, en realidad, se retrata la historia y vicisitudes de la nación argentina desde la vida de este gaucho defensor de su honor y su libertad. ¿Acaso no es el destino de toda verdadera obra de arte, de todo clásico, contar lo particular para hacer reflexionar sobre lo universal? Ese ha sido el destino de la obra española que mejor puede representar esa idea, el Quijote. Veamos otros dos ejemplos:

Aquí me pongo a cantar al compás de la vigüela, que el hombre que lo desvela una pena extraordinaria, como la ave solitaria con el cantar se consuela. (Hernández 1996, 15)

Con estos versos comienza el relato de Martín Fierro. Moreno Galván hace también su declaración de intenciones en la voz de Menese justo al comienzo del disco Cantes para el hombre nuevo (1971):

Vengo a cantar mis pesares,

a contar mis alegrías;

lástima que puedan más

en tan sangrienta partía

las penas de cada cual.

En otro destacado capítulo, el universo estético de Lorca es identificable, sobre todo, en las primeras letras escritas para José Menese en los años sesenta. Nada es gratuito, sin embargo. Se nombra a la guardia civil porque es parte de la vida del cantaor y de la sociedad de un pueblo que vivía con hambre y con miedo:

Que Dios te valga

si en la verea

sale la guardia.

Punta charol,

capa y bota,

a poquito a poco asoman,

igual que dos grajos verdes 
recortaos en la loma.

¡Ay! Más te valiera

que las lunas y soles

se confundieran.

Otro ejemplo similar lo encontramos en los martinetes:

A tres leguas de Triana

y por los campos juyío,

echarme una mano que vengo

por los jéres perseguío.

O en el mirabrás:

Con mil suores

puse en mi puerta

siete faroles.

Verte y no verte

y el candí de mi casa

no tiene aceite.

Los temas y recursos lorquianos son perfectamente identificables en el flamenco porque se han adaptado a él sin saberse bien si se trata de temas que eran parte del flamenco y Lorca descubrió, o si la poesía es tan sublime que ha sido capaz de enriquecer el corpus flamenco hasta ese punto. El hecho cierto es que hoy todo lector puede reconocer el aroma y perfume lorquiano en una letra; el riesgo residía en homenajear a Lorca con letras de este calado en los años sesenta.

Con respecto a las influencias de otros poetas de la generación del 27, pueden ser variadas. Primero porque es la generación que más y mejor se ocupó del flamenco o, por lo menos, de proteger y defender el estilo que hemos llamado popular. Así, no solo Rafael Alberti -basta leer, entre otras obras, La arboleda perdida-, como decía Galván en la entrevista, sino también Emilio Prados o José Bergamín son leídos y admirados por él. José Bergamín, en concreto, buen aficionado al flamenco, realizó una serie importante de coplas que podríamos llamar aforísticas:

Ni tú sabes ni yo sé, ni nadie supo ni sabe el porqué ni el para qué de que la vida se acabe. (Bergamín 2008, 652)

Un leitmotiv parecido propone el poeta morisco por fandangos:

Yo no sé ni lo sabré 
pero a mí me maravilla, un algo y un no sé qué, que en tanto no lo averigüe a mí me trae a maltraé. (Moreno Galván 1998, 229)

\section{LA LETRA FLAMENCA Y LO POPULAR EN LOS MACHADO}

La relación de la familia Machado con la letra popular representa de una forma muy gráfica la evolución personal de Francisco Moreno Galván en su búsqueda de la expresividad de la letra sin perder su capacidad poética, su trasfondo lírico, podríamos decir.

Antonio Machado y Álvarez (Santiago de Compostela, 1848-Sevilla, 1893) representa el espíritu primero que animó a Francisco cuando se inició a escribir letras flamencas. Se trataba de asimilar un estilo popular, anónimo, adoptar esa extraña sabiduría de la vida, de la fatiga, del contexto social y político de una época. La enseñanza de Demófilo es la del estudioso compilador de letras populares clásicas, siempre fiel admirador de la certerísima mirada de aquellos anónimos creadores:

[...] son más de una vez los respetabilísimos autores y autoras de las coplas de este libro, coplas que no conseguirán mejorar, ni aun sudando el quilo, los que, al escribir versos figurándose estar haciendo embuchados para la venta, estiran, estiran, estiran y rellenan, rellenan y rellenan sus composiciones poéticas, olvidándose del precepto de que la mejor poesía es la que dice más en menos palabras, y ni más ni menos que si intentasen parodiar el chacinero que aspira vender como carne lo que son piltrafas. (Machado y Álvarez 2005, 14)

Esa admiración se manifiesta más en la delicadeza con la que se realiza la trascripción fonética de la letra. Demófilo entiende que esos cantes trascienden lo meramente poético. Son letras, coplas, cante, y su creador posiblemente las hizo en su cabeza para pasar seguidamente a su garganta sin necesidad de darlas por escrito en ningún momento.

No es que la copla se pone en música como se puede poner en música una oda: es que la copla, verdaderamente real y espontánea, cuando nace, nace ella misma cantándose, si vale expresarse así. Una copla escrita es una obra estropeada. (Machado y Álvarez 2005, 16)

Ese es el espíritu verdadero con el que Moreno Galván comienza a escribir sus letras. Letras que, como dijimos anteriormente, transcribía fonéticamente a Menese para que fuesen cantadas. Letras que tenían que ver con 
la vida misma del cantaor, con sus penurias y alegrías... La identificación de Moreno Galván con el espíritu de Demófilo era total en esos primeros años.

Manuel Machado (Sevilla, 1874-Madrid, 1947) da un paso más en lo que se refiere a esa apuesta de su padre por lo popular. Su vocación es poética, su formación también lo es. Y en su vida fue fundamental viajar a París y el conocimiento y la lectura de Rubén Darío, poeta después del cual la poesía en castellano jamás volvería a ser la misma. Pero para entender el paso adelante con respecto a lo que había dejado su padre atenderemos concretamente al prólogo que escribió Miguel de Unamuno para el libro Alma. Museo. Los Cantares, de 1907. Pese a lo alejado que Unamuno parezca estar en un principio de esa poesía de corte más cercano a lo folclórico, es impresionante ver qué certera es su lectura y qué clarividente su comentario.

Esa cosa ligera, alada y sagrada que es a veces Manuel Machado resulta ser un verdadero clásico. Clásico en su sentido más extenso y universal, y clásico en su sentido más restricto y nacional, es decir, castizo. (Unamuno 1907, XI)

Por una parte, ve ese casticismo, esa voluntad universalista, indeterminada, anónima, que lo hace clásico porque lo saca de la mera autoría poética del momento (de cualquier momento). Pero Unamuno va un poco más allá en lo que tiene que ver con la forma de creación poética.

Machado no es un virtuoso de la versificación sino un poeta. El ritmo literal de sus cantos, el ritmo de su palabra, brota del ritmo espíritu de ellos, del ritmo de la idea. Es el contenido poético el que florece en forma armoniosa y melódica. [...] La de Machado es música; música interior de la que brota la exterior. (Unamuno 1907, XXVI)

De alguna manera esta declaración de Unamuno nos retrotrae a aquella del padre de los Machado en la que denosta a los versificadores. Hay en Manuel Machado una aspiración musical, a ser canto, a ser cante quizá. A estar cerca de esa poesía que se hace para ser cantada. Aunque son poemas, poemas de un gran poeta, los versos de Machado tienen muchas veces el encanto "clásico" de la letra flamenca.

En otro marco de actuación, la presencia de Antonio Machado Ruiz es permanente en lo ético y menos evidente en lo estético. Machado influye en su vertiente didáctica, la de Juan de Mairena. Esto es común en los dos hermanos (Francisco y José María); ambos eran, además, grandes conocedores de su poesía. Pero la creación de coplas o poemas de aroma popular es un género que Antonio Machado frecuentó poco. Sólo en Proverbios y cantares leemos una copla puntual que Moreno Galván reelaboró de una forma sutil. Así, la copla dice: 
Por dar al viento trabajo, cosía con hilo doble las hojas secas del árbol. (Machado 1962, 204)

Conserva todo el encanto poético en la letra para el flamenco:

Por darle qué hablá a la gente, me puse a pescar estrellas con una caña en la fuente. (Moreno Galván 1998, 156)

En esta letra Moreno Galván renuncia a un tema que pudiera sonar más flamenco a fin de atraer hacia el cante la poesía machadiana en todo su esplendor. Por otra parte, sobresalen las coplas "A la manera de Juan de Mairena, apuntes para una geografía emotiva de España", en la que se evocan paisajes jienenses y el carácter de sus gentes:

Sol de los montes de Baza.

Mágina y su nube negra.

En el Aznaitín afila

su cuchillo la tormenta.

¡Qué bien los nombres ponía

quien puso Sierra Morena

a esta serranía!

Tiene bastante que ver con el entusiasmo de las coplas que Francisco Moreno dedica a la ciudad de Ronda:

Benaoján bravía

y Ronda partía en dos

mirando la serranía.

Qué bien hicieron de Ronda

cuando a Ronda la partieron,

ciudad, mercaíllo y barrio

y los tres puentes en medio.

Indudablemente, hay una razón estética en la obra de Moreno, que viene marcada fuertemente por el contexto en la que se desarrolla y siempre con un vínculo personal, vital, anclado en el propio pueblo. El poeta Antonio Machado, en un artículo en el que respondía a las preguntas tolstoianas "¿qué es el arte?»y «qué debemos hacer?», planteaba lo siguiente:

El arte es juego en cuanto tiene de mimesis, de simulacro; pero su gran nobleza no consiste en copiar la vida despojándola de su contenido real, ni aun siquiera de emanciparla de la necesidad, del dolor y de la fatiga, porque entonces sería una superflua imagen en un espejo. [...] el arte es 
algo más: es, ante todo, creación. No es un jugar, es un hacer, no es juego supremo, sino un trabajo supremo, creativo, original. Tal es, al menos, mi opinión. (Machado 2001, 446)

Hondas y complejas son las conexiones vitales e intelectuales de los dos hermanos Moreno Galván con Antonio Machado. Nos detendremos en la estética, o ética estética a la manera juanramoniana, porque sienta las bases de la razón creativa que impulsa la obra de ambos moriscos. En la cita anterior, a la que muy posiblemente no tuvieron acceso ninguno de los dos hermanos, se resume de manera precisa, por una parte, el vínculo necesario entre el arte y la propia vida; pero, por otro, el compromiso con la creación, con el trabajo supremo, el arte visto como un mandato en el que el artista es una parte dentro del engranaje de la tradición artística o creativa. Pero Machado redunda más concretamente en el ¿qué hacer?:

Para terminar. Usted, mi querido Rivas Cherif, que tan oportunamente ha exhumado, con el viejo tema de Vida y Arte, las palabras del venerable Tolstoi, ha extremado su bondad para conmigo hasta preguntarme por mi obra actual. Le contestaré brevemente. Yo, por ahora, no hago más que folklore, auto-folklore o folklore de mí mismo. Mi próximo libro será, en gran parte, de coplas que no pretenden imitar la manera popular -inimitable e insuperable, aunque otra cosa piensen los maestros de retórica- sino coplas donde se contiene cuanto hay en mí de común con el alma que canta y piensa en el pueblo. Así creo yo continuar mi camino, sin cambiar de rumbo. (Machado 2001, 449)

La primera tentación al afrontar la relación de Francisco Moreno con la idea de lo popular en el arte es, claro, relacionarlo no con Antonio Machado Ruiz sino con Antonio Machado Álvarez, su padre. Pero es en Antonio Machado, el poeta, donde hay una evolución en la idea de lo popular que entronca directísimamente con la tradición que asume Francisco (y también José María en el plano teórico). Ese autofolklore o folklore de mí mismo del que habla Machado representa nítida y sencillamente un concepto complejisimo en el que lo formal tiende a reproducir el estilo de lo popular mientras que el fondo, la expresión, viene impuesto por el avatar vital del creador.

José María Moreno Galván ahondaba en esta idea en una conferencia leída a finales de los años cincuenta:

[...] para Berenson, lo mismo que para Croce, no obstante sus matices diferenciales, "el acto estético es forma y nada más que forma». ¿Nada más?, decimos nosotros. ¿Y qué hacemos con «lo jondo»? ¿Qué hacemos con las condiciones nacionales? ¿Qué hacemos con aquella sustancia que escapa de la cárcel de la forma, lo que constituye su expresión? Porque la forma, repito, es una cárcel impuesta por las ideas, mientras que la 
expresión es una subversión de las creencias. La expresión, lo jondo, es el elemento intuitivo y popular, el último grito de una primitividad sojuzgada por el intelectualismo de la forma ${ }^{6}$.

Como puede apreciarse, hay en esencia una fuerte ligazón con el texto machadiano. Pero José María Moreno Galván va un poco más allá usando la categoría de lo jondo en un contexto que nada tiene que ver en este caso con el flamenco sino con un concepto de arte genuinamente español. No obstante, la conferencia trataba precisamente sobre la posibilidad de que existiera una serie de características españolas en el arte contemporáneo de aquel tiempo. Por supuesto, en el espíritu del texto está la filosofía machadiana, pero estaban también, y lo estuvieron siempre en la obra de José María Moreno Galván, Unamuno y Ortega. La tensión entre la forma y la expresión es la tensión orteguiana entre la idea y la creencia. El clasicismo es la consecuencia de la intelectualización máxima de la forma, mientras que el primitivismo es consecuencia de la popularización de las creencias. José María se rebela ante la imposición del clasicismo a ultranza de su tiempo demostrando que en el arte español hay un expresionismo inherente que tiene que ver en su más profunda esencia con el sentimiento trágico de la vida unamuniano, tan español, y tan jondo, por otra parte.

Francisco Moreno Galván hace un arte necesario, un arte que él cree que es huella del momento y el lugar en el que vive. Su concepción del hecho artístico es primitiva, casi artesana. Se trata de una forma de entender el arte previa a la idea del «arte por el arte» o esteticismo instaurado desde el siglo XVIII a nuestros días. Esta idea de lo jondo intenta transmitir esa utilidad vinculada a la expresión vital, y ligada a su vez con el ser mismo del arte español.

La categoría de lo jondo trasciende todo academicismo, hunde sus raíces en lo popular. Es lo que atrae a Francisco a admirar el trabajo de herreros, carpinteros, alfareros..., y es lo que vincula su obra a la de estos hombres del pueblo. La condición de artista de Francisco es una condición machadiana, la condición que propugnaba que «Siempre que advirtáis un tono seguro en mis palabras, pensad que os estoy enseñando algo que creo haber aprendido del pueblo».

6. Conferencia: «Las constantes del arte en España». Ciclo de conferencias ofrecidas en Madrid en los años cincuenta. Se dirige al auditorio en femenino por lo que podría ser un ciclo organizado en una residencia universitaria femenina. En Martín Cabeza 2018, 328. 


\section{CONCLUSIÓN}

Es evidente que existe desde mediados del siglo XIX un interés por parte de poetas e intelectuales en el romancero y folclore llamado popular. Ese interés se hace más o menos patente a lo largo de las primeras décadas del siglo Xx y podríamos decir que se hace palpable con la generación del 27. Sin embargo, pensamos que hay maneras de demostrar que la sinergia entre lo popular y lo culto ha sido constante desde los albores de la literatura y sin lugar a dudar han estado nutriéndose la una a la otra sin prejuicios ni absurdas categorizaciones artificiales. En Francisco Moreno Galván se hace patente, y quizá por eso se evidencia más, un viaje en sentido contrario. Desde una posición de búsqueda de pureza de lo popular, del cante anónimo, el poeta va asumiendo que es imposible ahondar en ese terreno sin tener en cuenta la tradición poética de la literatura española. Esa tradición enriquece su poesía, enriquece al flamenco mismo porque en ningún caso le ha sido ajena nunca.

Por otro lado, se nos plantea la curiosa cuestión de la autoría. En cierto sentido lo que hace Moreno Galván, poner letra a las vicisitudes vitales del cantaor para que él las exprese, pensamos que puede ser algo que también forma parte de cómo se han creado muchas letras del flamenco por autores cercanos a los artistas que han asumido sus experiencias y traducido estas a versos para ser cantados.Los tres miembros de la familia Machado nos han servido asimismo para ejemplificar ese viaje que hizo el autor desde una posición casi antropológica, en la que no quiso contaminar de poesía el cante, más identificada con Demófilo, hasta una posición estética más conceptual que tiene que ver con el Machado de Juan de Mairena. Una posición que no abandona en ningún caso su absoluta predilección por lo popular, pero que asume que hay un componente personal, de autor, que puede repercutir de una manera política. Esto es fundamental en el desarrollo poético y estético de la obra de Francisco Moreno Galván y en la forma en que sigue perviviendo hoy en día en la voz de jóvenes artistas.

\section{Bibliografía}

Bergamín, José. Poesías Completas I. Valencia: Editorial Pre-Textos, 2008.

Fernández Bañuls, Juan Alberto y José María Pérez Orozco. Poesía flamenca, lírica en andaluz. Sevilla: Signatura Ediciones, 2003.

García Gómez, Génesis. José Menese. Biografía jonda. Madrid: El País Aguilar, 1996. 
Gutiérrez CARBajo, Francisco. La copla flamenca y la lírica de tipo popular. Madrid: Editorial Cinterco, 1990.

Gutiérrez CARBAjo, Francisco. La poesía del flamenco. Córdoba: Editorial Almuzara, 2007.

Hernández, José. El Gaucho Martín Fierro. Madrid: Biblioteca Edaf de Bolsillo, 1979.

Lope De Vega. Poesías Líricas de Lope de Vega. Madrid: Espasa Calpe, 1951.

Machado, Antonio. Poesías completas. Madrid: Espasa Calpe, 1962.

Machado, Antonio. Prosas dispersas (1893-1936). Madrid: Páginas de Espuma, 2001.

MACHADO, Antonio. Juan de Mairena. Madrid: Cátedra, 2003.

Machado y Álvarez, Antonio. Colección de Cantes Flamencos. Madrid: Ediciones de Cultura Hispánica, 1975.

Machado y Álvarez, Antonio. Cantes Flamencos y Cantares. Biblioteca de Autores sevillanos. Edición de Enrique Rodríguez Baltanás. Sevilla: Diputación de Sevilla-Fundación Machado, 2005 [1881].

Martín Cabeza, Juan Diego. Estética de lo Jondo. Poesía y pintura de Francisco Moreno Galván. Sevilla: Editorial Universidad de Sevilla, Sevilla, 2018.

MenÉndez Pidal, Ramón. Antología de poetas líricos castellanos. Santander: Aldus, 1944.

Menéndez PIDAL, Ramón. Flor Nueva de Romances Viejos. Madrid: Espasa Calpe, 1959.

MENÉNDEZ Pidal, Ramón. Estudios sobre el Romancero. Madrid: Espasa Calpe, 1973.

Moreno Galván, Francisco. Letras flamencas completas. La Puebla de Cazalla, 1998.

PiÑero Ramírez, Pedro M. (ed.). De la canción de amor medieval a las soleares. Sevilla: Universidad de Sevilla, 2004.

Piñero, Pedro M., Enrique Baltanás y Antonio Pérez Castellano. Romances y Canciones en la tradición andaluza. Sevilla: Fundación Machado, 1998.

Quevedo, Francisco de. Poesía de España, la muerte y Dios. Madrid: Editorial NyC, 1980.

Quevedo, Francisco de. Poesía varia. Ed. de James O. Crosby. Madrid: Cátedra, 1992.

Rodríguez-PuÉRTOlas, Julio. Poesía crítica y satírica del siglo XV. Madrid: Clásicos Castalia, 1981.

Unamuno, Miguel de. "La poesía de Manuel Machado". En Machado, Manuel. Alma. Museo. Los Cantares. Madrid: Librería de Pueyo, 1907, pp. VII-XXVIII. 
